\title{
Research on Modeling and Control of Regenerative Braking for Brushless DC Machines Driven Electric Vehicles
}

\author{
Jian-ping Wen ${ }^{1,2}$ and Chuan-wei Zhang ${ }^{1}$ \\ ${ }^{1}$ School of Mechanical Engineering, Xi'an University of Science and Technology, Xi'an 710054, China \\ ${ }^{2}$ Key Laboratory of Expressway Construction Machinery, Chang'an University, Xian 710054, China \\ Correspondence should be addressed to Jian-ping Wen; wenegle@gmail.com
}

Received 30 January 2015; Revised 16 July 2015; Accepted 21 July 2015

Academic Editor: Eric Florentin

Copyright ( 2015 J.-p. Wen and C.-w. Zhang. This is an open access article distributed under the Creative Commons Attribution License, which permits unrestricted use, distribution, and reproduction in any medium, provided the original work is properly cited.

\begin{abstract}
In order to improve energy utilization rate of battery-powered electric vehicle (EV) using brushless DC machine (BLDCM), the model of braking current generated by regenerative braking and control method are discussed. On the basis of the equivalent circuit of BLDCM during the generative braking period, the mathematic model of braking current is established. By using an extended state observer (ESO) to observe actual braking current and the unknown disturbances of regenerative braking system, the autodisturbances rejection controller (ADRC) for controlling the braking current is developed. Experimental results show that the proposed method gives better recovery efficiency and is robust to disturbances.
\end{abstract}

\section{Introduction}

Electric vehicles have been catching more attention as a means of eliminating or reducing exhaust gas emission from vehicles and dependence on oil in recent years [1]. However, the driving distance of $\mathrm{EV}$, particularly battery electric vehicle $(\mathrm{BEV})$, is limited by the energy in the battery [2]. One of the most important features of the $\mathrm{EV}$ is ability to recover braking energy when vehicle is under braking [3]. The electric motor can be controlled to produce the proper amount of braking force for recovering braking energy as much as possible which can be stored in the battery and then reused to increase the driving distance and energy efficiency.

In order to improve energy efficiency and dynamic braking performance of regenerative braking, many researchers developed the control strategies for EV. Based on the modern control theory, some control strategies are applied to regenerative braking for EV $[4,5]$. Reference [6] designed the mathematical models of driving and regenerative braking and researched neural network sliding mode controller to improve and recover more energy. Reference [7] proposed a cooperative regenerative braking control algorithm for a sixspeed automatic transmission based parallel hybrid electric vehicle. There is a fuzzy logic control strategy to adjust the regenerative braking torque dynamically for a parallel hybrid electric vehicle and improve regenerative braking energy recovery rate of $\mathrm{EV}[8,9]$. Adaptive regenerative braking control strategy is applied to determine the braking command to guarantee the maneuvering capability [10]. Reference [11] adopts the constant current control strategies to obtain stable braking torque and improve energy recovery efficiency.

BLDCM has been widely used in EV because it is more efficient and is more readily controlled than the AC motors [12]. So, regenerative braking of battery-powered EV based on BLDCM is discussed in this paper. In order to avoid the damage on batter caused by large braking current, the braking current of regenerative braking is controlled. According to power circuit topology, the model of braking current is established, on the basis of which autodisturbances rejection controller is designed to realize good control effects of regenerative braking.

\section{Mathematical Model of BLDCM}

Assuming star connected windings, no neutral line, ignoring cogging effect, homogeneous distribution windings, ignoring 


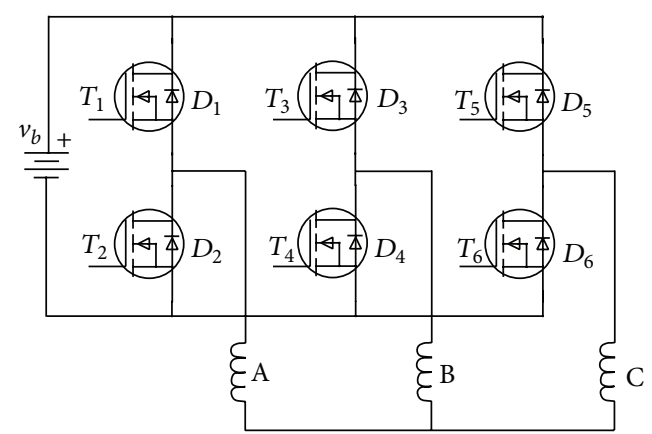

Figure 1: Power circuit structure.

saturation of magnetic circuit, eddy-current loss and magnetic hysteresis loss, and no damping winding on rotor and damping effect of magnet, the voltage equation of stator windings is expressed as [13]

$$
\left[\begin{array}{l}
u_{a} \\
u_{b} \\
u_{c}
\end{array}\right]=G\left[\begin{array}{l}
i_{a} \\
i_{b} \\
i_{c}
\end{array}\right]+p N\left[\begin{array}{l}
i_{a} \\
i_{b} \\
i_{c}
\end{array}\right]+\left[\begin{array}{l}
e_{a} \\
e_{b} \\
e_{c}
\end{array}\right],
$$

where $p$ is differential operator, $u_{a}, u_{b}$, and $u_{c}$ are phase voltages of three-phase stator windings, respectively, $i_{a}, i_{b}$, and $i_{c}$ are phase currents of three-phase stator windings, respectively, and $e_{a}, e_{b}$, and $e_{c}$ are back-emf three-phase stator windings, respectively. Parameters $G$ and $N$ are denoted as, respectively,

$$
\begin{aligned}
G & =\left[\begin{array}{lll}
R & 0 & 0 \\
0 & R & 0 \\
0 & 0 & R
\end{array}\right], \\
N & =\left[\begin{array}{ccc}
L-M & 0 & 0 \\
0 & L-M & 0 \\
0 & 0 & L-M
\end{array}\right],
\end{aligned}
$$

where $R$ is resistance of the stator windings, $L$ is selfinductance of the stator windings, and $M$ is mutual inductance of the stator windings.

\section{Modeling of Regenerative Braking}

3.1. Regenerative Braking Process Analysis. Topological structure of three-phase driving circuit for brushless DC machine is shown in Figure 1.

With phases $a$ and $b$, for example, when EV travels in drive power modes, the power switch $T_{1}$ is in PWM and the others are off. The power system is in the buck running mode, which is shown in Figure 2.

When EV travels in electric power generation, the BLDCM runs at generating mode and the power circuit is the same with drive power mode. The current flows in the stator windings in opposite direction. According to rotor position signals, the control system modulates the low power switches of inverter and charges the battery based on the

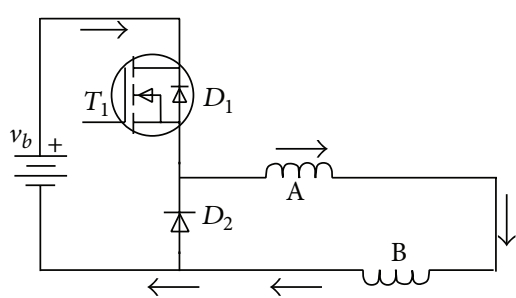

FIGURE 2: The electrical circuit of driving of BLDCM.

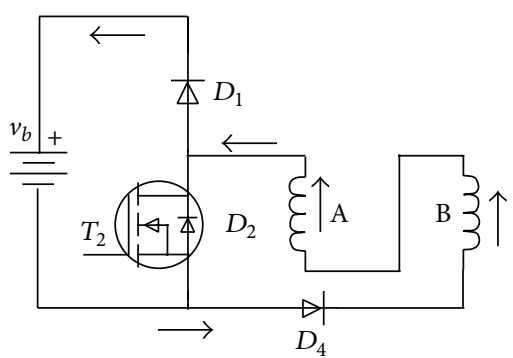

FIGURE 3: The electrical circuit of regenerative braking of BLDCM.

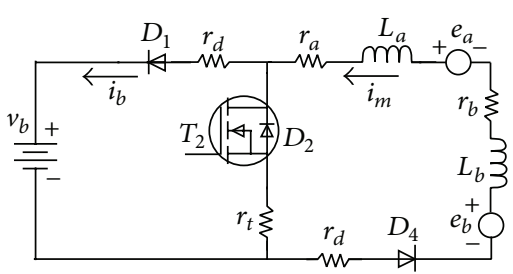

FIGURE 4: Equivalent circuit of regenerative braking.

boost chopper principle by self-inductance of windings. The kinetic energy of EV is converted to electric energy to feed the battery.

With phases $a$ and $b$, for example, the power switch $T_{2}$ runs under the PWM mode in the process of generative braking. The others are in stop state. The battery is charged by raising back-emf of BLDCM. The electrical circuit of regenerative braking of BLDCM is shown in Figure 3.

Equivalent circuit of regenerative braking is shown in Figure 4. $r_{t}$ is equivalent series resistance of power switch, $r_{d}$ is equivalent series resistance of diode, $L_{a}, r_{a}$, and $e_{a}$ are inductance, resistance, and back-emf of phase $a$, respectively, $L_{b}, r_{b}$, and $e_{b}$ are inductance, resistance, and back-emf of phase $b$, respectively, $i_{b}$ is braking current, and $i_{m}$ is current of stator winding.

According to the voltage equation, the three stator windings can be regarded as the same; there are $L_{a}=L_{b}=L_{m}$, $e_{a}=e_{b}=e_{m}$, and $r_{a}=r_{b}=r_{m}$.

During the $T_{2}$ turning on $(0 \leq t \leq d \cdot T)$, the voltage balance equation of main circuit is expressed as

$$
2 L_{m} \frac{d i_{m}}{d t}=2 e_{m}-i_{m} \cdot\left(2 r_{m}+r_{d}+r_{t}\right) .
$$


During the $T_{2}$ turning off $(d \cdot T<t \leq T)$, the voltage balance equation of main circuit is expressed as

$$
2 L_{m} \frac{d i_{m}}{d t}=2 e_{m}-v_{b}-i_{m} \cdot\left(2 r_{m}+2 r_{d}+r_{\text {bat }}\right),
$$

where $d$ is PWM signal's duty cycle, $T$ is PWM signal's period, and $r_{\text {bat }}$ is internal resistance of battery.

By averaging PWM on-time and PWM off-time of $T_{2}$, the voltage balance equation is expressed as

$$
2 L_{m} \frac{d i_{m}}{d t}=m i_{m}+2 e_{m}-(1-d) v_{b}
$$

where $m=(d-2) r_{d}-d r_{t}+(d-1) r_{\text {bat }}-2 r_{m}$.

The electromagnetic torque can be expressed as

$$
J \frac{d \omega}{d t}=-K_{t} \cdot i_{m}-T_{L},
$$

where $K_{t}$ is torque coefficient, $T_{L}$ is the load torque, $J$ is the combined machine and load inertia coefficient, and $\omega$ is rotor angular velocity.

3.2. Modeling of Charging Current. The EV usually adopts battery as energy storage equipment. For protecting the battery against the damage by large charging current, the charging current is controlled. So, (5) can be rewritten as

$$
i_{m}=S i_{m}+Q,
$$

where $S=\left((d-2) r_{d}-d r_{t}+(d-1) r_{\text {bat }}-2 r_{m}\right) / 2 L_{m}$ and $Q=\left[2 e_{m}-(1-d) v_{b}\right] / 2 L_{m}$.

$S$ is decomposed into two parts and expressed as

$$
S=\frac{(d-2) r_{d}-d r_{t}+(d-1) r_{\text {bat }}}{2 L_{m}}-\frac{r_{m}}{L_{m}}=S_{1}-S_{2} .
$$

By substituting (8) in (7), the charging current $i_{m}$ is expressed as

$$
\dot{i}_{m}=-S_{2} i_{m}+S_{1} i_{m}+Q
$$

\section{Design of Regenerative Braking ADRC Controller}

4.1. ADRC. The typical ADRC consists of nonlinear tracking differentiator (TD), extended state observer (ESO), and nonlinear state error feedback control law (NLSEF) [14, 15]. By using extended state to observe the disturbances, nonlinear uncertain system can be approximate linearization. The second-order ADRC is shown in Figure 5.

$v$ is input signal, $v_{1}$ is tracking input signal, $v_{2}$ is the differential $v_{1}, u$ is control signal, $y$ is system output, $z_{1}$, $z_{2}$, and $z_{3}$ are state variables, $e_{0}$ and $e_{1}$ are state error, $u_{0}$ is uncompensated control signal, and $b$ is constant.

In $n$-order system, the TD is used to export the transient process tracking command and derivative. If the plant is one-order system, the TD becomes a filter. The disturbances observed by the ESO are entered into nonlinear state error function and the control signal is obtained.

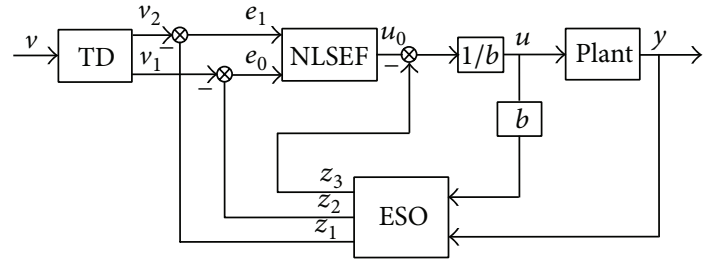

FIgURE 5: Flowchart of the ADRC controller.

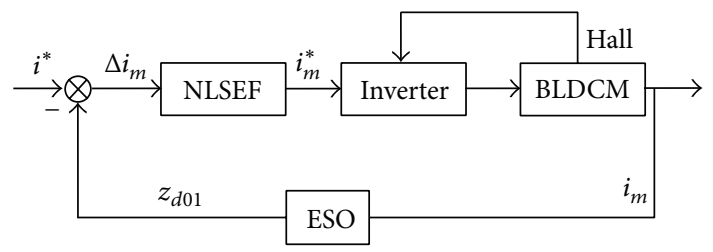

FIGURE 6: Flowchart of regenerative braking of BLDCM.

The ESO of the second-order system can be expressed as

$$
\begin{aligned}
& \dot{z}_{1}=z_{1}-e_{0}, \\
& \dot{z}_{2}=z_{3}-\beta_{01} \cdot \operatorname{fal}\left(\varepsilon_{1}, \alpha_{1}, \delta_{1}\right)+b \cdot u, \\
& \dot{z}_{3}=\beta_{02} \cdot \operatorname{fal}\left(\varepsilon_{2}, \alpha_{2}, \delta_{2}\right),
\end{aligned}
$$

where $\beta_{01}, \beta_{02}, \alpha_{1}, \alpha_{2}, \varepsilon_{1}, \varepsilon_{2}, \delta_{1}$, and $\delta_{2}$ are adjustable parameters.

Nonlinear function, $\mathrm{fal}(\varepsilon, \alpha, \delta)$, can be denoted by

$$
\mathrm{fal}(\varepsilon, \alpha, \delta)= \begin{cases}|\varepsilon|^{\alpha} \operatorname{sign}(\varepsilon), & |\varepsilon|>\delta \\ \frac{\varepsilon}{\delta^{1-\alpha}}, & |\varepsilon| \leq \delta .\end{cases}
$$

4.2. Regenerative Braking ADRC Controller. In the braking current model, the back-emf and internal resistance and so on are difficult to detect. According to the function of ESO, $\left(S_{1} i_{m}+Q\right)$ in (9) is regarded as disturbances; the second-order ESO of the braking current can obtained as follows:

$$
\begin{aligned}
e_{d} & =z_{d 01}-i_{m}, \\
\dot{z}_{d 01} & =-A_{2} i_{m}+z_{d 02}-\beta_{d 01} \mathrm{fal}\left(e_{d}, \alpha_{d 01}, \delta_{d}\right), \\
\dot{z}_{d 02} & =-\beta_{d 02} \mathrm{fal}\left(e_{d}, \alpha_{d 02}, \delta_{d}\right),
\end{aligned}
$$

where $z_{d 01}$ is used to estimate braking current, $z_{d 02}$ is extended state variable, and $e_{d}$ equals the difference between estimator and output current.

In the charging process of regenerative braking, the braking current $i_{m}$ is first-order model. NLSEF is established as

$$
\begin{aligned}
\Delta i_{m} & =z_{d 01}-i^{*}, \\
i_{m}^{*} & =k_{d} \operatorname{fal}\left(\Delta i_{m}, \alpha_{m}, \delta_{m}\right) .
\end{aligned}
$$

The regenerative braking control model of BLDCM is shown in Figure 6. 


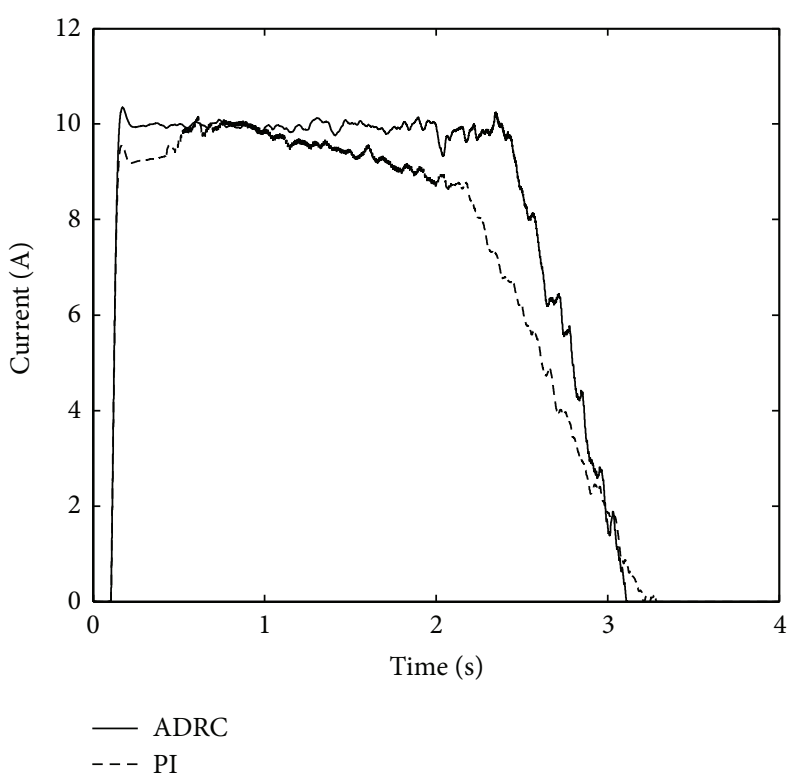

FIGURE 7: The braking current response (a DC-link voltage of $290 \mathrm{~V}$ and initial velocity of $200 \mathrm{rad} / \mathrm{s}$ ).

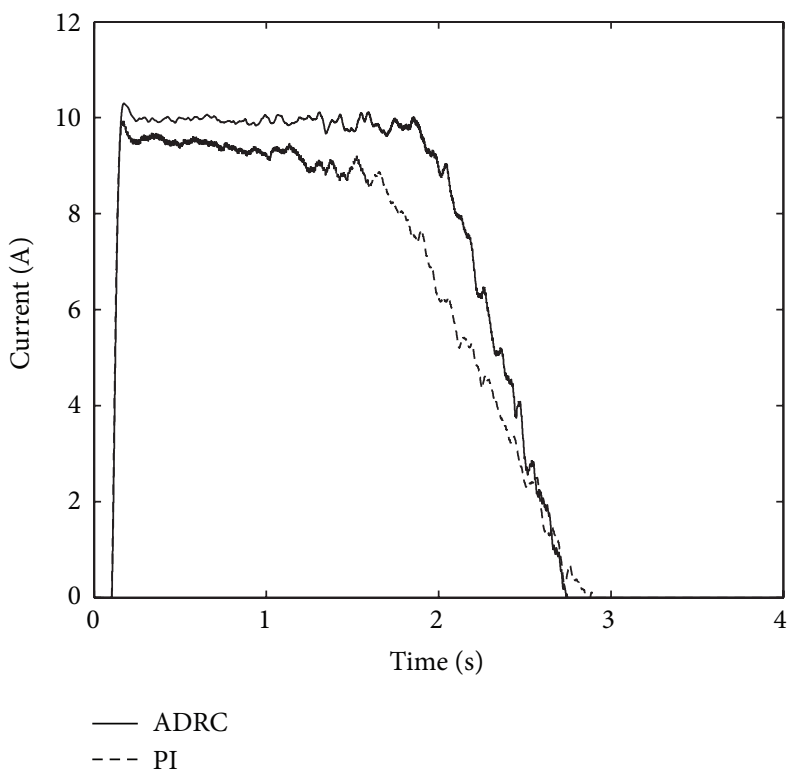

FIGURE 8: The braking current response (a DC-link voltage of $280 \mathrm{~V}$ and initial velocity of $150 \mathrm{rad} / \mathrm{s}$ ).

\section{Results and Analysis}

5.1. Simulation Modeling. A simulation model of regenerative braking of the BLDCM shown in Figure 6 is implemented using Matlab/Simulink to verify the braking current model and the proposed ADRC control method, as well as in comparison with standard PI controller.

Initial velocity and the battery voltage in regenerative braking are principal influence factors. Under different initial velocity and the battery voltage conditions, the simulations of regenerative braking were done by using ADRC controller and PI controller, respectively. The braking current instruction value is $10 \mathrm{~A}$ in regenerative braking. $\beta_{d 01}=3000, \beta_{d 02}=$ 10000, $\alpha_{d 01}=\alpha_{m}=0.25, \alpha_{d 02}=0.5, \delta_{d}=\delta_{m}=0.1$, and $k_{d}=1.6$. The $i_{m}$ is obtained by detecting the current of DC bus.

Figures 7 and 8 show the braking current response in the simulation.

It is seen that the amplitude of the actual braking current is less than that of the reference by using PI controller. When using ADRC controller, the braking current response and steady-state error are improved. Even if the initial velocity 


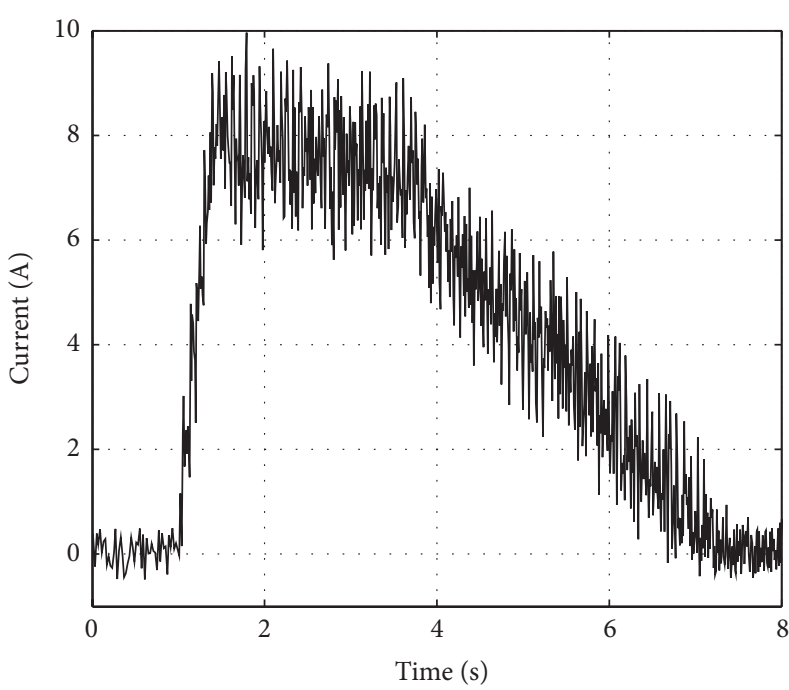

(a) PI controller

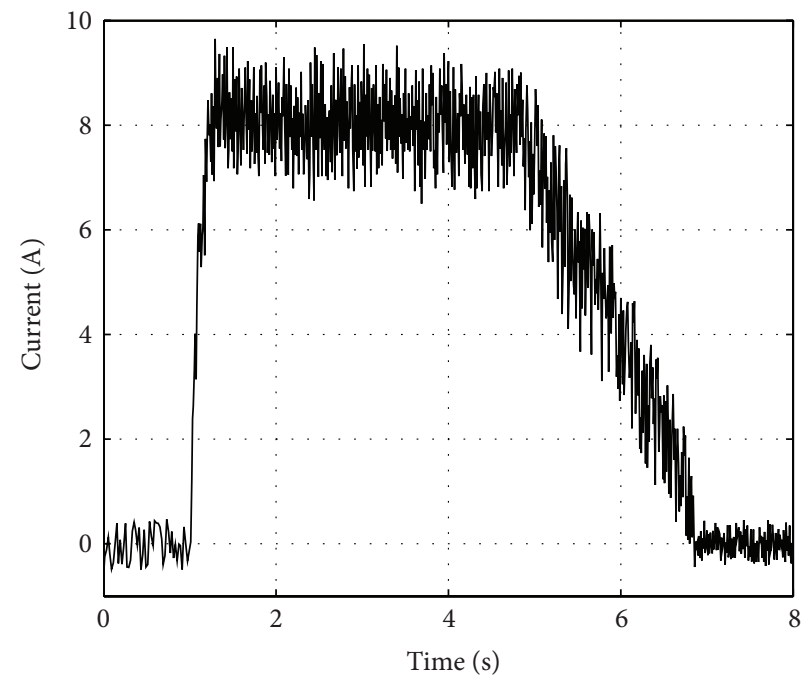

(b) ADRC controller

FIGURE 9: The braking current response at $35 \mathrm{kph}$.

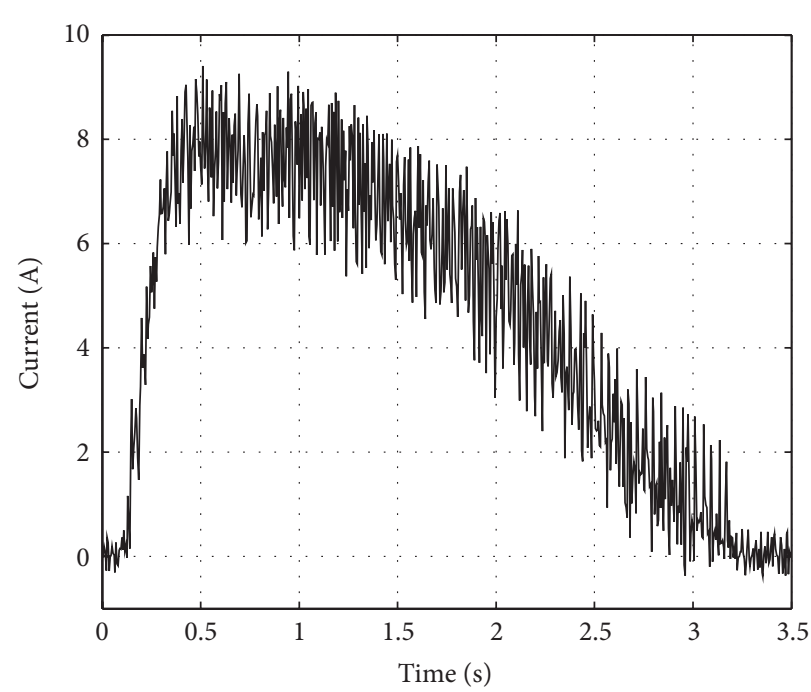

(a) PI controller

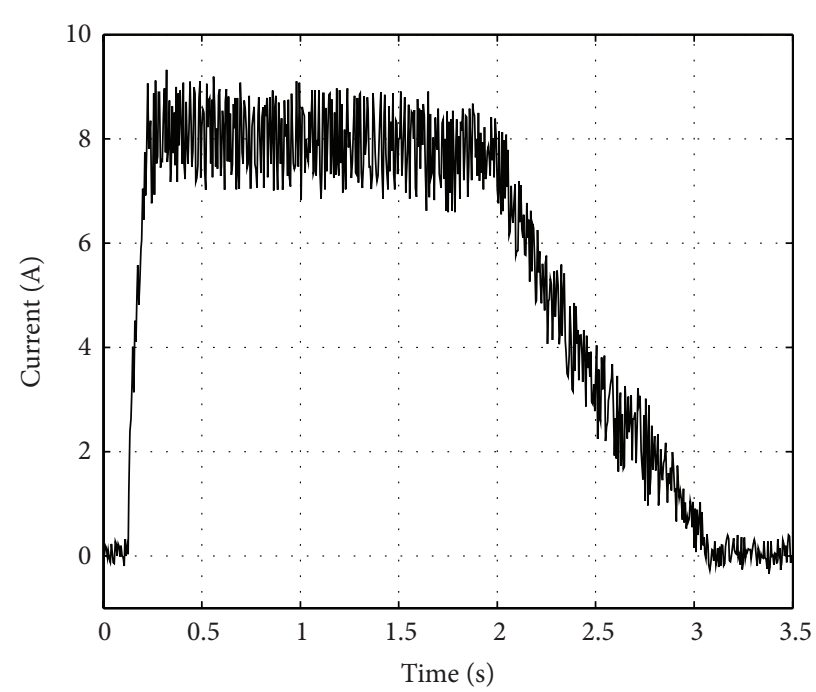

(b) ADRC controller

FIGURE 10: The braking current response at $20 \mathrm{kph}$.

and volt DC change, the ADRC controller still maintains the good control effect.

5.2. Experimental Result. In order to verify the validity of the designed model in real system, the two-wheel electrical motorcycle is chosen for experiment. The battery voltage is $48 \mathrm{~V}$. The constant braking current control is used. The braking current reference is $8 \mathrm{~A}$. Figures 9 and 10 show the braking current responses, respectively.

The change of the battery voltage is small in the process of one-time regenerative braking recovery. If the battery voltage is viewed as constant, the amount of energy recovery is proportional to braking current within a given period. Faster response and smaller steady-state error of braking current mean that the energy recovery increase and the recovery efficiency is improved. Simulation results show that the performance of braking current ADRC controller is superior to that of PI controller.

\section{Conclusions}

In this paper, on the basis of the equivalent circuit of regenerative braking, the braking current model of BLDCM has been discussed in the battery-powered EV regenerative braking energy recovery. The ADRC control method of braking current based on ADRC and braking current model has been proposed.

The performance of the ADRC controller is verified by modeling based on Matlab/Simulink and experimental result. 


\section{Conflict of Interests}

The authors declare that there is no conflict of interests regarding the publication of this paper.

\section{Acknowledgments}

This study is supported by the Key Laboratory of Expressway Construction Machinery (Chang'an University), Shaanxi province, no. 310825151135, and by the Special Fund for Basic Scientific Research of Central Colleges, Chang'an University, no. $0009 / 310825140044$.

\section{References}

[1] A. Kabasawa, K. Kimura, T. Taguchi, and A. Anekawa, "Development of a new powertrain for subcompact electric vehicles," SAE Technical Paper 2013-01-1478, SAE, 2013.

[2] M. Miller, A. Holmes, B. Conlon, and P. Savagian, "The GM 'Voltec' 4ET50 multi-mode electric transaxle," SAE International Journal of Engines, vol. 4, no. 1, pp. 1102-1114, 2011.

[3] H.-X. Wu, S.-K. Cheng, and S.-M. Cui, "A controller of brushless DC motor for electric vehicle," IEEE Transactions on Magnetics, vol. 41, no. 1, pp. 509-513, 2005.

[4] Z.-F. Bai, B.-G. Cao, S.-X. Li, and L.-Y. Kang, "Simulation on $H_{\infty}$ robust control for regenerative braking of electric vehicle," Journal of System Simulation, vol. 17, no. 12, pp. 2975-2978, 2005.

[5] M. Ye, S. Jiao, and B. Cao, "Energy recovery for the main and auxiliary sources of electric vehicles," Energies, vol. 3, no. 10, pp. 1673-1690, 2010.

[6] J.-B. Cao and B.-G. Cao, "Neural network sliding mode control based on on-line identification for electric vehicle with ultracapacitor-battery hybrid power," International Journal of Control, Automation and Systems, vol. 7, no. 3, pp. 409-418, 2009.

[7] C. Jo, J. Ko, H. Yeo, T. Yeo, S. Hwang, and H. Kim, “Cooperative regenerative braking control algorithm for an automatictransmission-based hybrid electric vehicle during a downshift," Proceedings of the Institution of Mechanical Engineers, Part D: Journal of Automobile Engineering, vol. 226, no. 4, pp. 457-467, 2012.

[8] G. Yin and X. Jin, "Cooperative control of regenerative braking and antilock braking for a hybrid electric vehicle," Mathematical Problems in Engineering, vol. 2013, Article ID 890427, 9 pages, 2013.

[9] M. Zhou, S. Bi, C. Dong, and C. He, "Regenerative braking system for electric vehicles based on genetic algorithm fuzzy logic control," ICIC Express Letters, Part B: Applications, vol. 5, no. 3, pp. 689-695, 2014.

[10] S. Jansen, M. Alirezaei, and S. Kanarachos, "Adaptive regenerative braking for electric vehicles with an electric motor at the front axle using the state dependent riccati equation control technique," WSEAS Transactions on Systems and Control, vol. 9, pp. 424-437, 2014.

[11] K. Zhou, L. Chen, C. Pan, L. Chen, and X. Wang, "Electric vehicle regenerative braking system based on constant current control of composite power sources," Journal of Mechanical Engineering, vol. 49, no. 20, pp. 78-83, 2013.

[12] H.-S. Chuang, Y.-C. Chuang, and C.-Y. Chen, "Development of two-quadrant PMDC motor drives with regenerative braking on electric vehicles," ICIC Express Letters, vol. 5, no. 9, pp. 33213328, 2011.

[13] B. Abdi, H. Bahrami, and S. M. M. Mirtalaei, "Simplified design and optimization of slotless brushless DC machine for micro-satellites electro-mechanical batteries," Journal of Electrical Engineering and Technology, vol. 8, no. 1, pp. 124-129, 2013.

[14] J. Q. Han, "Auto disturbances rejection control technique," Frintier Science, vol. 1, pp. 24-31, 2007.

[15] Y. X. Su, C. H. Zheng, and B. Y. Duan, "Automatic disturbances rejection controller for precise motion control of permanentmagnet synchronous motors," IEEE Transactions on Industrial Electronics, vol. 52, no. 3, pp. 814-823, 2005. 


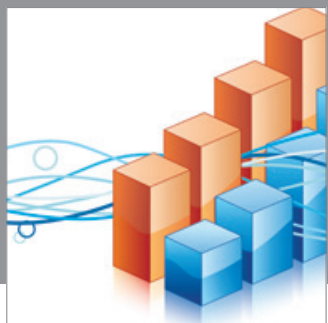

Advances in

Operations Research

mansans

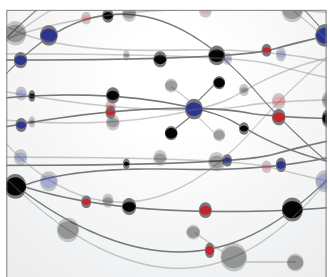

The Scientific World Journal
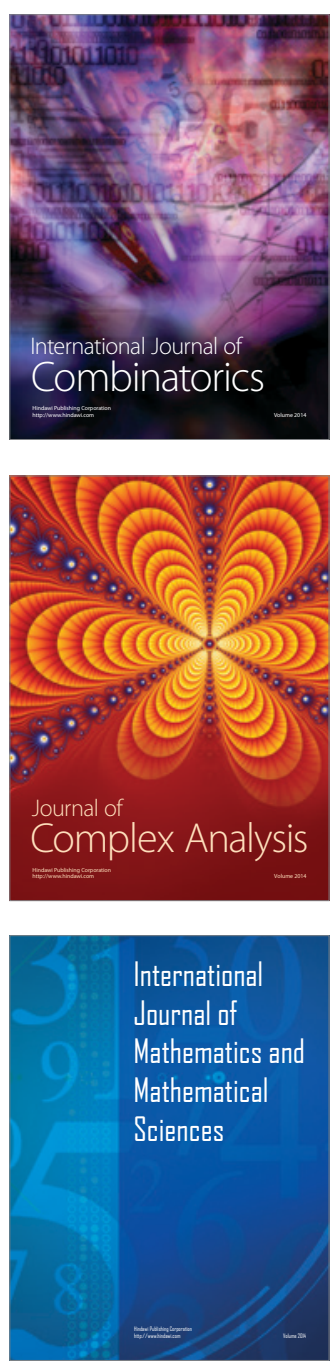
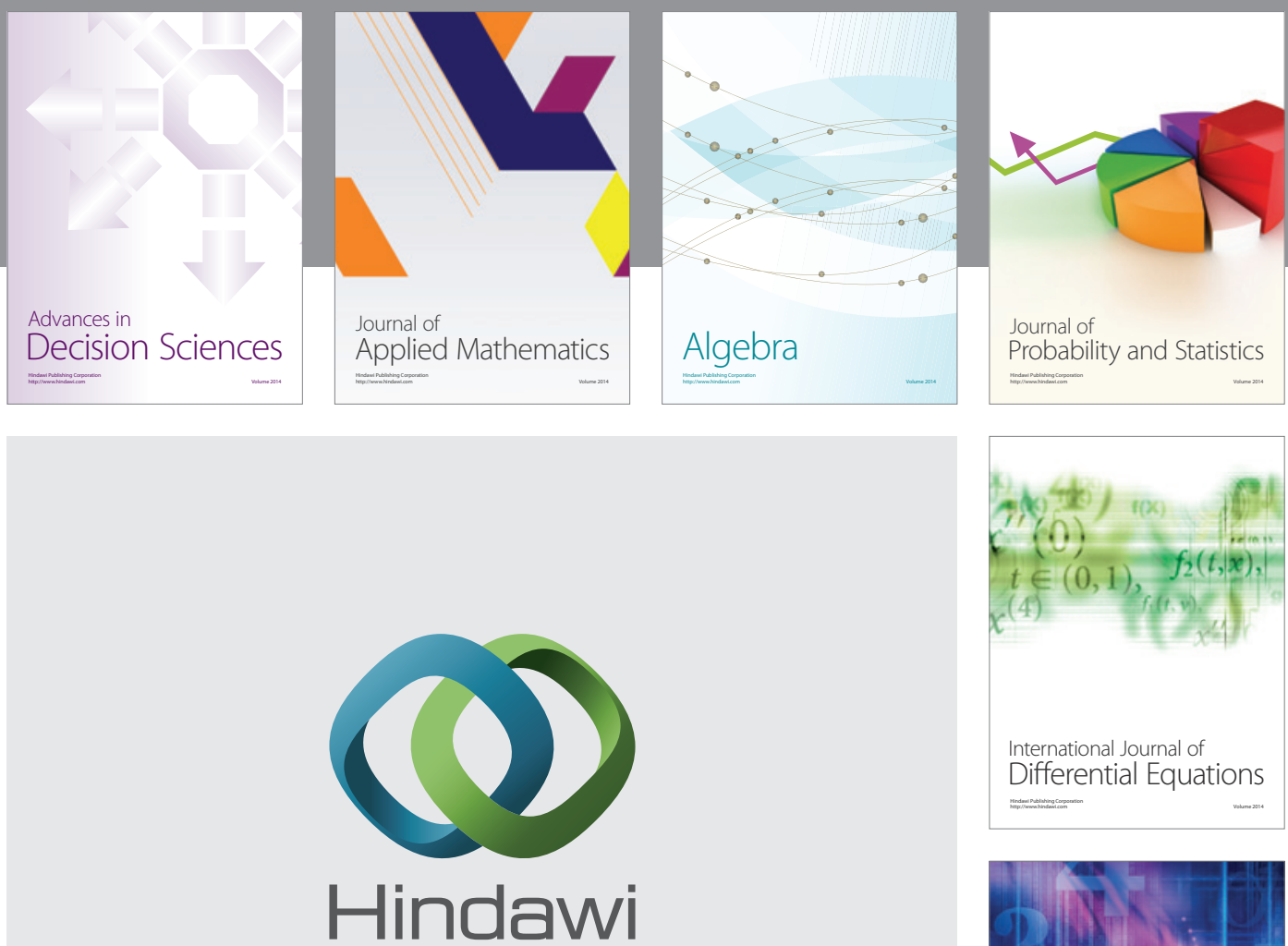

Submit your manuscripts at http://www.hindawi.com
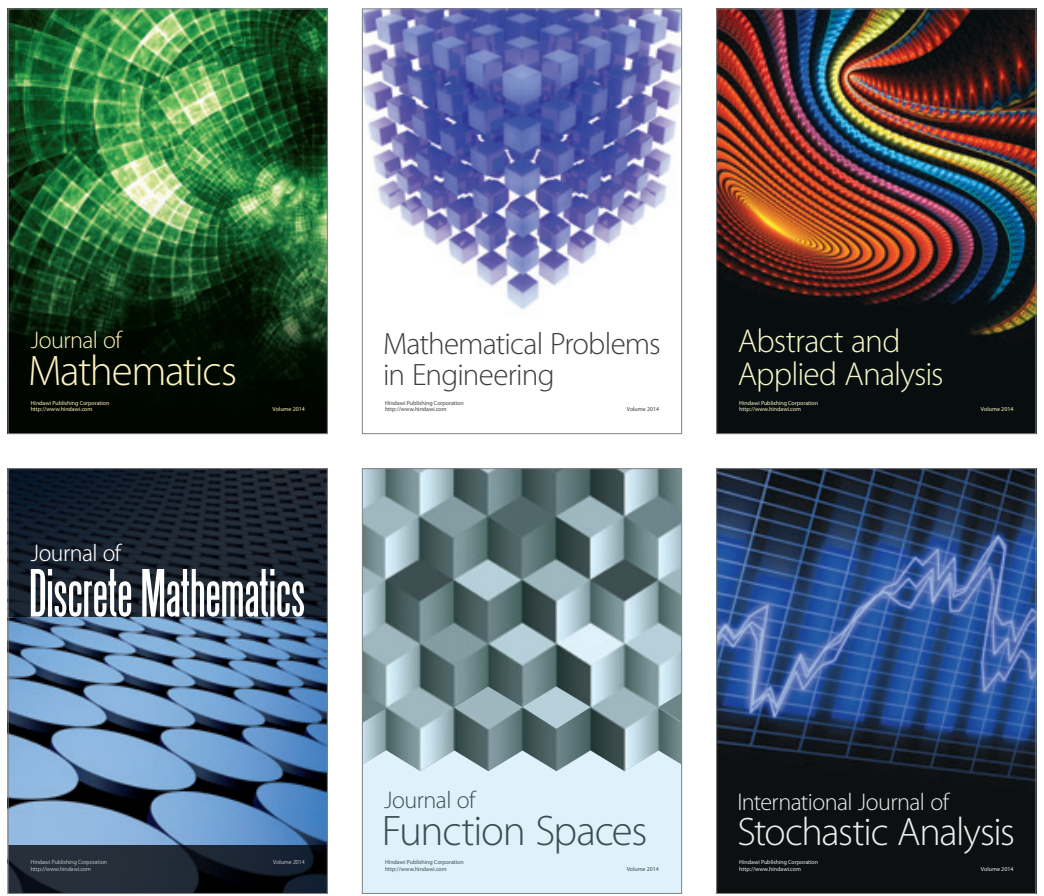

Journal of

Function Spaces

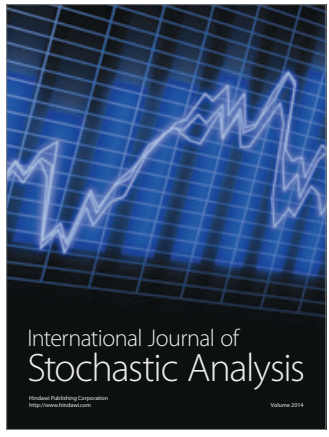

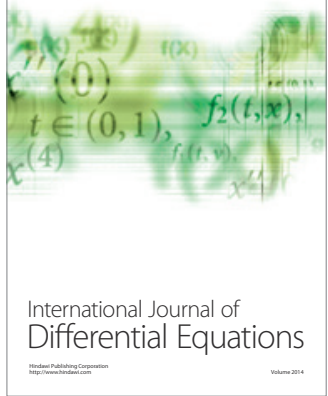
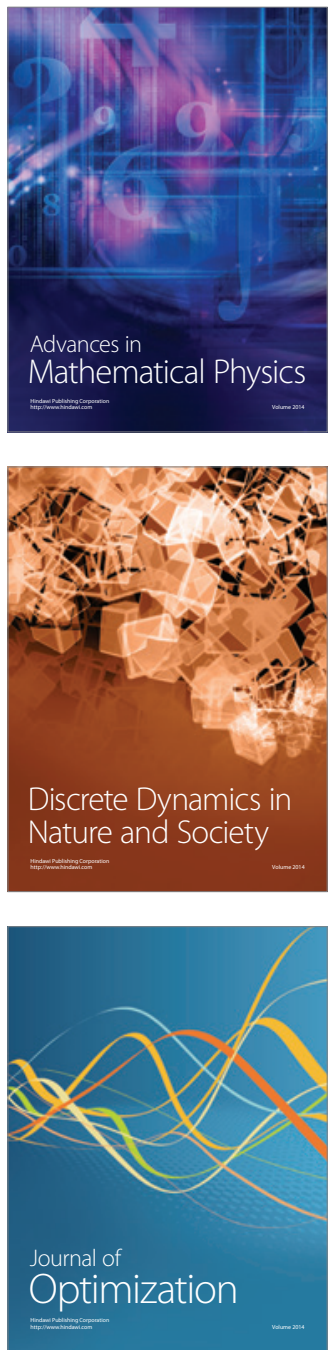